\title{
A IDEIA DE NAÇÃO NO PENSAMENTO DE PASQUALE STANISLAO MANCINI
}

\section{Chiara Antonia Sofia Mafrica Biazi}

Doutoranda no Programa de Pós-Graduação em Direito da UFSC. Mestre em Direito e Relações Internacionais pela mesma instituiç̧ão. Formada em Direito pela Università degli Studi di Trento (Italia) e pela UFSC (revalidação de diploma). Membro do grupo de pesquisa em Direito Internacional Ius Gentium/CNPq. merceau@hotmail.it

\section{Resumo:}

Este trabalho pretende estudar os conceitos de nacionalidade e de nação assim como os mesmos foram desenvolvidos pelo jurista italiano Pasquale Stanislao Mancini no contexto da Escola Italiana de Direito Internacional do século 19. A partir da análise da teoria desenvolvida pelo autor, será possível entender como a mesma representa uma ruptura com os postulados da ciência internacional clássica de tradição contratualista, por colocar a "nação" no lugar do "Estado" como sujeito de Direito Internacional.

\section{Palavras-chave:}

Pasquale Stanislao Mancini. Escola Italiana de Direito Internacional. Princípio de nacionalidade. Nação. Estado.

\section{THE IDEIA OF NATION IN PASQUALE STANISLAO MANCINI'S THOUGHT}

\section{Abstract:}

This article intends to analyse the concepts of nationality and nation as developed by the Italian jurist, Pasquale Stanislao Mancini in the context of the Italian school of international Law of the 19 th century. By analysing the theory developped by the author, it will be possible to understand how it represents a rupture with the assumptions of the classical science of international Law of contratualism, since replaces the "State" with the "Nation".

\section{Keywords:}

Pasquale Stanislao Mancini. Italian School of International Law. Principle of nationality. Nation. State.

\section{Revista}

\section{DIREIT0 \& Debate}


Recebido em: 24/3/2017

Aceito em: 11/8/2017

\section{Sumário:}

1 Introdução. 20 contexto histórico-jurídico. 3 A teoria da nacionalidade em Pasquale Stanislao Mancini. 4 Considerações finais. 5 Referências. 


\section{INTRODUÇÃO}

A noção de nacionalidade concebida como conceito jurídico teve origem na elaboração da Escola Italiana de Direito Internacional do século 19, cujo maior representante foi Pasquale Stanislao Mancini. Os juristas liberais desta escola criaram a assim chamada teoria do "princípio de nacionalidade" como "fundamento do direito das gentes", desenvolvendo, a seguir, o conceito de nacionalidade sobre o qual basear o reconhecimento da nação itálica. $\mathrm{O}$ conceito de nação assim como desenvolvido por Mancini e a sua escola refletia o ideal liberal do século 19, ou seja, que as naçôes, uma vez alcançados os seus objetivos de organização interna, deveriam conviver pacificamente. Com a elaboração dessas novas teorias, produz-se uma ruptura com a concepção até aquele momento fortemente arraigada segundo a qual o Estado era o supremo sujeito de Direito Internacional.

O século 19 foi um período marcante para História da humanidade e, da mesma forma, para o desenvolvimento do Direito Internacional. Após o Congresso de Viena de 1815 e a derrota de Napoleão em Waterloo, os povos, traídos por falsas esperanças, tratados como mercadoria em virtude da reformulação das fronteiras europeias, despertaram e, em uníssono, em vários países europeus, ergueram-se para reivindicar seu próprio papel na definição dos rumos da História. As esperanças advindas das mudanças prometidas pela Revoluçáo Francesa foram traídas novamente pela Restauração e pela instauração do princípio do legitimismo. Desde Vestfália os Estados - criação da modernidade - estavam comprometidos com a manutenção do equilíbrio político, confiando um papel relevantíssimo à diplomacia. Teatro de inúmeros movimentos revolucionários, a Europa testemunhou o despertar de nacionalidades, que, por muito tempo, permaneceram sufocadas. $\mathrm{O}$ ideal predominante dessas ondas revolucionárias foi o nacionalismo. Muitos países europeus, como Itália, Alemanha, Polônia, e o antigo Império Austro-Húngaro, foram atravessados por agitaçóes populares - núcleo da "primavera dos povos", nas palavras de Hobsbawm - que visavam a libertar suas próprias pátrias do domínio estrangeiro, imposto pelas decisōes do Congresso de Viena. 


\section{CONTEXTO HISTÓRICO-JURÍDICO}

As teorias italianas sobre a nacionalidade receberam impulso por parte do Romantismo e também pelo Iluminismo. A ideia de nação era implícita na concepção do Romantismo: o sentimento de liberdade e de personalidade, o significado da natureza, o impulso à espontaneidade, a tensão para com o advir. Esses e outros aspectos da concepção do Romantismo incluíam a ideia de que, assim como os indivíduos, também para os povos devia se reivindicar uma individualidade aderente à natureza, oriunda do mesmo sentimento de possuir esta individualidade, todavia no quadro de uma harmonia universal e humana da solidariedade das gentes (CURCIO, 1950).

No que diz respeito à influência do Iluminismo no próprio conceito, é possível constatar a presença de uma acentuada percepçáo do universal, no qual a pessoa coletiva adquire um papel relevante, assim como a angústia de se livrar dos velhos esquemas, das fórmulas convencionais para ceder lugar às formas de vida ligadas às exigências históricas e morais dos povos. O Iluminismo e a idade napoleônica tinham plantado as sementes da ideia de nação. Apesar, contudo, das influências evidentes do movimento iluminista antes e romântico depois sobre o pensamento da Escola Italiana de Direito Internacional, deve-se ressaltar que, mesmo entre os juristas italianos de Oitocentos, o princípio de nacionalidade apresentava-se com traços peculiares, tanto em relação à reflexão dos iluministas da estação tardo-setecentista, quanto em relação às teorias aparecidas nas naçôes pré-unitárias $^{1}$ (COLAO, 2001).

O século aqui considerado foi atravessado por uma série de agitaçôes ${ }^{2}$ que deixaram as suas próprias marcas na História da humanidade: os movimentos revolucionários que se espalharam pela Europa inteira após o Congresso de Viena de 1815, determinado a queda de Napoleão Bonaparte. Nesse sentido:

\footnotetext{
${ }^{1}$ A autora afirma que com a unidade italiana, a ideia de uma necessária respondência entre naçáo e Estado, funcional para oferecer a esse último um fundamento de legitimidade, afirmava-se em virtude de um conceito, a naçáo, posta acima de interesses e ideologias particularistas, e enquanto tal apta a juntar o povo ao seu Estado.

2 Ver a respeito do despertar das nacionalidades no período napoleônico a contribuiçáo de Carlo Francovich. $\mathrm{O}$ autor analisa o despertar do sentimento nacional em vários países durante o período napoleônico e após a derrota do personagem. FRANCOVICH, Carlo. Il Risveglio delle nazionalità nel
} 
A queda de Napoleão, tendo sido causada igualmente pelos seus erros políticos e pelo despertar das nacionalidades que ele tinha demasiadamente contido fez um culto do passado e foi imensamente útil para descobrir e estudar todo aquilo que era nacional. Os povos ficaram desiludidos após a paz, já que nenhuma das promessas feitas pelos seus príncipes para colocá-los contra o estrangeiro tinha sido mantida. Os tratados de 1815 dividiram-nos como um rebanho de ovelhas e choraram pela perda das instituições francesas progressivas, nascidas da revolução de 1789, sem readquirirem a sua própria nacionalidade. [...] Agora os povos podem ressurgir do túmulo, eles pararam de ser o apanágio dos príncipes e se tornaram pessoas juridicas, que escolhem seu próprio governo e seus principes ${ }^{3}$ (LIOY, 1863, p. 10, grifo nosso).

Assim sendo, a partir do Congresso de Viena de 1815, assistiu-se a uma transformação profunda no cenário internacional. Desde os tratados de Vestfália, os Estados estavam profundamente preocupados com a manutenção do equilíbrio político e a diplomacia jogava um papel fundamental. Nesse contexto, a situação política da península italiana não era das mais felizes: a Itália, mesmo sendo geograficamente uma península compacta, era retalhada em inúmeros Estados subjugados e dominados há séculos pelas potências estrangeiras. Diferentemente de muitos Estados europeus que tinham se constituído e comparecido no panorama internacional já há séculos, a Itália chegou tardiamente no cenário internacional como Estado unido. As lutas políticas, os movimentos de libertação nacional para

periodo napoleonico. In: Atti del convegno Internazionale di Portoferraio (21-23 febbraio 1981). Pisa: Giardini Editori, p. 5-16. Para ulteriores leituras interessantes, ver: HOBSBAWM, Eric J. Nazioni e nazionalismo dal 1780. Torino: Giulio Einaudi Editore, 1991, traduzione di Piero Arlorio, em que o autor discute as várias formas que o nacionalismo tomou ao longo dos séculos 18, 19 e 20 e a obra de: WEILL, Georges. L'Europe du XIX siècle et l'idée de nationalité. Paris: Éditions Albin Michel, 1938, na qual o autor, partindo da origem da ideia de nacionalidade, explora como tal conceito foi desenvolvido na Itália e na Alemanha, ressaltando como esse se revigorou a partir do Congresso de Viena, contrapondo-se ao princípio do legitimismo, difundido a partir da Restauração.

3 Tradução livre de: 'La caduta di Napoleone essendo stata causata in pari tempo da' suo' errori politici e dal destarsi delle nazionalità che aveva troppo compresse fece un culto del passado e giovò immensamente a scovrire e studiare tutto ciò ch'era nazionale. I popoli rimasero delusi dopo la pace, poichè nessuna delle promesse fatte da' loro principi per rivolgerli contro lo straniero era stata mantenuta. I trattati del 1815 li divisero come un branco di pecore e piansero la perdita delle progressive istituzioni francesi, nate dalla rivoluzione dell'89, senza riacquistare la loro nazionalità. [...] Ora i popoli possono sorgere dalla tomba, essi hanno cessato di essere l'appannaggio de principi e son divenuti persone giuridiche, che scelgono il loro governo ed i loro principi." 
conquistar a tão aspirada independência foram acompanhados pela elaboração jurídica de intelectuais que desenvolveram contribuiçóes doutrinárias voltadas à formação de uma consciência nacional.

É necessário apontar que, mesmo não sendo o discurso sobre a "nação" " algo desconhecido anteriormente, todavia ele recebeu maior atenção ao longo do século 19, acompanhando e instigando as lutas em vários países europeus. A Itália, apesar de ter se constituído em Estado ao tardar do século 19, desde antes mantinha traços que a conduziam a obter também aquela unidade política tão aspirada.

A consciência que a nação italiana havia de si mesma não foi algo que surgiu improvisadamente no século 19, sendo resultado de um procedimento bem mais complexo, iniciado anteriormente. De fato:

[...] a nação italiana, que tinha alcançado com o Ressurgimento sua concretização como Estado, não era, nem podia ser uma criação nova, produto de uma situaçáo contingente; era, e devia ser, uma realidade histórica, um dado de fato que tinha encontrado no Ressurgimento sua consagração, mas que tinha o seu fundamento em uma evolução secular, cujas origens remontavam aos séculos até o limiar da história ${ }^{5}$ (LIOY, 1863, p. 1-2).

Antes mesmo do próprio Mancini, encontram-se as contribuições de vários intelectuais. Gian Domenico Romagnosi é o primeiro filósofo que atribuiu de forma definida uma função determinante à nação, posta no âmago da natureza e da

${ }^{4}$ Nação é um conceito bastante delicado e pouco claro. Citando uma definição: "The notion of nation is decidedly unclear, disputed and politically sensitive. [...] However, in most contexts the term refers to the psychological and political basis of political unity. Moreover, in democratic systems, it designates the general disposition to accept majority decisions even if they are against one's own interests. But even in this respect it does not refer to a single theory, but rather to a whole range of different and sometimes contradictory concepts connected to the generation of such a psychological or political basis. Therefore the notion of nation was and still is of utmost importance for political and legal thought and it is probably upon the very vagueness of the notion that its usefulness is based" In: VON BOGDANDY, Armin e HAUBLER, Stefan. Nations. In: The Max Planck Encyclopedia of Public International Law. Oxford University Press, 2012. p. 518.

5 Tradução livre de: "[...] la nazione italiana, la quale aveva col Risorgimento raggiunto la sua realizzazione come Stato, non era, non poteva essere uma creazione nuova, il prodotto di una situazione contingente; era, doveva essere, uma realtà storica, un dato di fatto che aveva trovato nel Risorgimento la sua consacrazione, ma che aveva il suo fondamento in una evoluzione secolare, le cui origini risalivano nei secoli sino alle soglie della storia." 
História. A nação é natureza: território, clima e gentes; mas também é história por ser uma formaçáo gradual, último estágio de desenvolvimento dos Estados (ROMAGNOSI, 1842, p. 1.057). Consta também como importante a contribuição de Giuseppe Mazzini, considerado um dos personagens mais importantes no panorama da unificação italiana. As primeiras definições de Mazzini de nação e nacionalidade remontam aos anos 1831 e 1832 . Na sua obra Istruzione generale per gli affrateIlati nella "Giovane Italia”, ele escrevia: "a Nação é a universalidade dos Italianos, unidos como irmãos em um pacto” (MAZZINI, 1935, p. 45), acrescentando que "para fundar uma Nacionalidade é necessária a consciência desta nacionalidade". Conforme sustenta Arno dal Ri Júnior,

a proposta de Mazzini tinha origens em um cosmopolitismo próximo ao iluminista, partindo do pressuposto de que esta nova "Nação" deveria ser universal e democrática, composta por homens que "[...] formam um só grupo, reconhecem um mesmo princípio, e se voltam, sob a égide de um direito comum, à obtenção de um mesmo fim”. Esta, porém, viria construída a partir de algo pré-existente, uma nação "histórica" redescoberta através da língua e de costumes comuns, além do fato de se pertencer a uma mesma etnia. A nação "histórica" também teria entre seus pressupostos outros elementos que não possuem uma natureza étnica, ou seja, vínculos criados pela história comum, como as convicções democráticas comuns, as regras que juntos os cidadãos escolhem através de sufrágio universal são o cimento que manterá coesa a construção étnica (2011, p. 78).

Luigi Taparelli d'Azeglio afirmava que elementos principais da nação são essencialmente a comunidade de origem e a linguagem e ainda antes, a unidade religiosa. Não fundamentais eram a forma de governo e o território, considerados secundários e acessórios. Mais detalhadamente em relação à forma de governo que alguns escritores democráticos consideravam como necessária para haver-se nacionalidade, Taparelli fazia questão de afirmar que se tratava de acidente conexo demasiadamente à "libido humana” (TAPARELLI D’AZEGLIO, 1849). Enquanto para Taparelli podia existir nacionalidade sem independência, Gioberti - que distinguia ao interior da nacionalidade uma espécie natural e uma artificial, a primeira obra da natureza, a segunda das ordens civis e do governo - afirmava que se um povo fosse submetido a outro, a nacionalidade artificial substituía a natural e assim a nação cessava de existir (GIOBERTI, 1846). Somente em uma hipótese 
Gioberti admitia que pudesse existir o domínio de um povo sobre outro: a saber, quando se tratasse de naçóes adultas que sustentavam naçóes jovens para ajudá-las a se tornarem adultas (1846).

\section{A TEORIA DA NACIONALIDADE EM PASQUALE STANISLAO MANCINI}

Durante o período histórico do Risorgimento italiano, uma das vozes mais fortes entre os juristas, Pasquale Stanislao Mancini, tinha posto como cerne de sua construção teórica a "nação", chamada a dar legitimação ao direito da Itália a se erguer como Estado nacional e a se tornar o âmago das instituiçóes estatais. Entre os estudiosos que desenvolveram o conceito de naçáo, Pasquale Stanislao Mancini a substitui ao Estado como sujeito de Direito Internacional.

Pasquale Stanislao Mancini ficou conhecido nos ambientes intelectuais da Itália meridional pela sua brilhante atividade de jurista, e tendo aderido ao movimento constitucional em Nápoles em 1848, teve de abandonar a sua terra nativa para enfim desembarcar como exilado em Turim, capital do Reino de Sardenha, lugar onde começou a frequentar os ambientes mais cultos, ganhando fama e apreciação como advogado e jurista. Emblemática foi a instituição da cátedra de Direito Público Externo e Internacional Privado na Universidade de Turim por meio da lei especial de 14 de janeiro de 1850, ocasião em que Mancini foi convidado a pronunciar um discurso perante a comunidade acadêmica e os jovens estudantes de Turim. Para inaugurar a referida cátedra, o jurista escolheu um tema bastante inédito e até então pouco explorado, dedicando a "prelezione" de 22 de janeiro de 1851 à digressão em torno da nacionalidade. Tal data é também considerada a data de nascimento no mundo científico da escola italiana de Direito Internacional. ${ }^{6}$

\footnotetext{
6 "Ben a ragione la scuola di diritto Internazionale che fonda le sue idee sul Principio di Nazionalità, riconoscendo delle Nazioni la esistenza ed il diritto, e che da questo principio trae il suo atteggiamento e nella scienza del giure e nella pratica della politica, può passare alla storia con l'appellativo di scuola italiana. Può infatti la sua data di nascita nel mondo scientifico del diritto internazionale facilmente fissarsi in quel 22 gennaio 1851 in cui Pasquale Stanislao Mancini, illustre figura di mente e di cuore partenopeo profugo ed ospite nella regale Torino, saliva nell'Ateo Subalpino la prima cattedra di diritto internazionale pronunciando la prolusione "Della nazionalità come fondamento del diritto delle genti", che é rimasta una delle opere più apprezzate e feconde in questo campo". In: PENNISI, Pasquale. Della applicazione del principio di nazionalità ai popoli di civiltà non europea. Padova: Cedam, 1931. p. 1.
} 
Na conferência "Do princípio de nacionalidade como fundamento do direito das gentes" Mancini proclama a ideia que na gênese do direito internacional, a nação, e não o Estado, representava a unidade elementar, a mônada racional da ciência (2003). O jurista reconhecia a fundamental importância de formar nas consciências, antes do que nas praças ou nos campos de batalha, o terreno da unidade nacional. Ele ressaltava como essa experiência precisava ser transformada de sentimento em conceito filosófico, de aspiração instintiva em predicado da razão, de paixão patriótica em disciplina jurídica.

Aparece claro desde o começo de sua celebérrima conferência o intuito do jurista italiano: instituir uma ciência, aquela da nacionalidade, promovendo "um conhecimento razoável e exato das condiçôes constitutivas da Nacionalidade, da solidez do fundamento jurídico da mesma, da santidade dos direitos que ela póe em exercício"7 (MANCINI, 1851, p. 8) A ideia de nacionalidade, que tinha permanecido "uma vaga aspiração, um generoso desejo, um tormento dos espíritos", agora estava prestes a renascer junto ao renascimento do Direito Internacional.

Após dedicar algumas páginas à história do Direito Internacional e a alguns nomes ilustres que deram contribuiçóes inestimáveis no tocante a essa disciplina, o jurista apresenta a tese de que, na gênese do Direito Internacional, seria a nação e não o Estado a "mônada" racional da nascente ciência. Ele considera a família e a nação as duas formas perpétuas de associação humana, por serem

\begin{abstract}
Ambas filhas da natureza e não da arte, companheiras inseparáveis do homem social mesmo onde a sociedade doméstica ou patriarcal náo deixa ainda enxergar um distinto rudimento de sociedade política, ambas possuem a origem santa, porque são igualmente revelações muito eloqüentes dos destinatários da criação, da constituição natural e necessária da Humanidade (MANCINI, 1851, p. 30, grifo no original).
\end{abstract}

\footnotetext{
Traduçáo livre de: "[...] una conoscenza ragionevole ed esatta delle condizioni costitutive della Nazionalità, della solidità del suo giuridico fondamento, della santità dei diritti cui essa pone in esercizio".

8 Tradução livre de: "Figlie entrambe della natura e non dell'arte, compagne inseparabili dell'uomo sociale anche dove la società domestica o patriarcale non lascia scorgere ancora un distinto rudimento di società politica, hanno entrambe santa l'origine, perché sono egualmente rivelazioni eloquentissime dédestinati della creazione, della costituzione naturale e necessaria dell'Umanità."
} 
Mancini destaca como cada povo é constituído por algumas características comuns - região, raça, ${ }^{9}$ língua,${ }^{10}$ costumes, a história, ${ }^{11}$ lei, religião ${ }^{12}$ - que fazem com que se instaure uma relação de intimidade e de comunhão de direito, impossível de se criar entre indivíduos de naçóes diferentes. A nação seria caracterizada pelos elementos materiais, os elementos geográficos, culturais, étnicos que distinguem os indivíduos que fazem parte dela dos indivíduos das outras naçóes. Sendo a nação constituída por esses elementos materiais, contudo, eles não são suficientes para que se possa conceber a nacionalidade. Eis aqui a inserção do elemento fundamental para que se possa formar uma nação: a consciência da nacionalidade. Citando as palavras de Mancini:

Esses elementos são como matéria inerte capaz de viver, mas sobre os quais não foi ainda exalado o sopro da vida. Ora, esse espírito vital, essa divina concretização do ser de uma nação, esse princípio da sua visível existência em que consiste?

9 "A raça, expressão de uma identidade de origem e de sangue, é outro importante elemento constitutivo da nação. É exatamente com essa relação que a nação mais retrata a família [...] entre os homens há uma evidente pluralidade de raças com caracteres mais ou menos distintos [...]”. In: MANCINI, Pasquale Stanislao. Direito internacional. (Diritto Internazionale. Prelezioni). Ijuí: Ed. Unijuí, 2003. p. 57.

10 "De todos os vínculos de unidade nacional, porém, nenhum é mais forte que a língua comum. [...]. Ora, o que indica o grande número de línguas senão o providencial destino da sociedade humana de se compor de muitas nacionalidades distintas, cada uma com vida e existência próprias? E as línguas dos povos deixam menor incerteza que os traços característicos e as formas do corpo. Em nenhum outro setor revelam-se melhor o gênio e a condição intelectual de uma nação do que em seu idioma e nas peculiaridades que distinguem o mesmo. Nas linguas se reflete também a filiaçâo das raças. Vico, Leibnitz e Bacon acreditam igualmente que nelas se pode estudar melhor que em outros setores as histórias nacionais. Não resta a menor dúvida que a unidade da língua manifesta a unidade da natureza moral de uma nação e cria suas ideias dominantes." In: Idem, Ibidem.

11 "Por último, nas tradiçōes da glória nacional e na história das geraçōes passadas, um povo adquire a consciência do caminho percorrido por seu espirito. E suas próprias se tornam o eco ingênuo e fiel das paixöes, dos sofrimentos e da vida moral e social de toda a nação". In: Idem, Ibidem.

12 "Das conformidades precedentes surgem depois ou se auxiliam todas as demais que se reduzem às crenças religiosas, aos costumes, às leis e às instituiçōes. Um secreto e incessante processo de assimilação desenvolve desse modo um espirito e uma tendência nacional que o tempo fortalece e lhe confere formas mais esculpidas, sendo que em dois povos não são jamais de todo semelhantes. Por vezes coisas que num país são consideradas essenciais para as necessidades da humanidade, nunca atraíram o desejo de outra nação e uma terceira delas se ofende como se fossem um ultraje. Cada nação apresenta múltiplas formas de prazer e a criação dos males é muitas vezes obra da mesma. Que profundas diversidades de todo tipo devem produzir entre dois paises somente as diferenças de uma religiäo monoteista ou politeista e a poligamia ou a monogamia na constituição da família? In: Idem, Ibidem. 
Senhores, esse é a CONSCIÊNCIA DA NACIONALIDADE, o sentimento que ela adquire de si mesma e que a torna capaz de se constituir internamente e de se manifestar externamente ${ }^{13}$ (1851, p. 38-39, grifo no original).

Tal elemento espiritual que complementa e completa os elementos materiais é apontado como imprescindível para a constituição de uma nação. A mera existência de características comuns compartilhadas pelos indivíduos não é suficiente para a existência de uma nação: para isso é necessário possuir uma consciência de constituir um mesmo povo, o elemento psicológico que torna esses aglomerados de traços comuns possíveis instrumentos para se alcançar a devida independência da nação.

Resumindo, o autor define nacionalidade como “[...] sociedade natural de homens com unidade de território, de origem, de costumes e de língua, configurados numa vida em comum e numa consciência social” (MANCINI, 1851, p. 41). Entre os elementos materiais que compóem uma nação, o jurista confere um destaque peculiar à língua, ao apontar que nenhum outro elemento revela tão perfeitamente a condição intelectual de uma nação e que "[...] a unidade da linguagem manifesta a unidade da natureza moral de uma nação, e cria as suas ideias dominantes"14 (MANCINI, 1851, p. 37, grifo no original).

Como antes já destacado, o elemento espiritual ${ }^{15}$ da nação é aquele que confere vitalidade e que é imprescindível, posto que sem ele os elementos materiais são inertes. Esse elemento espiritual, psicológico foi denominado por alguns juristas

${ }^{13}$ Tradução livre de: "Questi elementi son come inerte materia capace di vivere, ma in cui non fu spirato ancora il soffio della vita. Or questo spirito vitale, questo divino compimento dell'essere una Nazione, questo principio della sua visibile esistenza, in che mai consiste? Signori, esso é la COSCIENZA DELLA NAZIONALITÀ, il sentimento che ella acquista di sé medesima e che la rende capace di costituirsi al di dentro e di manifestarsi al di fuori"..

${ }^{14}$ Tradução livre de: "[...] Che l'unità del linguaggio manifesta l'unità della natura morale della Nazione, e crea le sue idee dominanti."

${ }^{15}$ Conforme Flavio Lopez de Ońate, o verdadeiro precursor de Mancini, no tocante ao elemento psicológico, é Giuseppe Mazzini, onde além do elemento Saint-simoniano do but commun d'activité, faz-se presente e necessária a consciência nacional. Existem, contudo, alguns elementos que diferenciam as concepçóes de Mazzini e de Mancini: o primeiro possui uma visáo mais universal, que abrange o inteiro campo da ética, enquanto para Mancini a consciência da nacionalidade indica a individualidade dos povos, não possuindo aquele alcance universal. Para Lopez de Ońate, dois são os elementos 
de "sentimento nacional". ${ }^{16}$ Mancini refere-se à consciência que a nação possui de si mesma, de fato, ela é "o sentimento que ela adquire de si mesma e que a torna capaz de se constituir internamente e de se manifestar externamente. [...] ela é o Penso, logo existo dos filósofos, aplicado à nacionalidade"17 (MANCINI, 1851, p. 39, grifo no original). Esse elemento espiritual ${ }^{18}$ confere coerência aos elementos materiais, que diversamente seriam matéria incoerente, sem algum amálgama.

que caracterizam o pensamento de Mancini: a consciência da nacionalidade e a nação como sujeito de direito internacional. In: LOPEZ DE ON̈ATE, Flavio. Introduzione. In: MANCINI, Pasquale Stanislao. Saggi sulla nazionalità. Bergamo: Sestante, 1944.

${ }^{16}$ Um aluno de Mancini, Giuseppe Carle, explica que o seu maestro insere esse elemento psicológico como um instrumento que sucessivamente teria servido como princípio organizador do Estado moderno. Carle destaca como Mancini procurou tornar esse elemento psicológico um elemento científico da sua teoria, configurando-se como fundamental para significaçāo dos demais elementos. In: CARLE, Giuseppe. Pasquale Stanislao Mancini e la teoria psicologica del sentimento nazionale. In: Atti della R. Accademia dei Lincei, classe di scienze fisiche e morali, VI, 1889, p. 553. Assim também ver em Droetto "Di quel processo di integrazione, nel quale, come insegna il Carle, consiste la fase moderna della formazione dello Stato, in confronto al miscuglio di elementi politici, economici e sociali che ne costituiscono la struttura medievale, la pubblicistica italiana del secolo XIX rappresenta lo stadio avanzato dell'analisi psicologica, istituita allo scopo di sostituire all'artificio dell'equilibrio politico la considerazione delle aspirazioni concrete dei popoli." In: DROETTO, Antonio. Pasquale Stanislao Mancini e la scuola italiana di diritto internazionale del XIX secolo. Milano: Giuffré, 1954, p. 159. Esse ressalte sobre o elemento psicológico é realizado também por Carnazza Amari, deputado parlamentar e internacionalista, que ao comemorar o personagem de Mancini, já falecido, afirma que "Il Mancini, proclamando il principio di nazionalità, venne anche emancipandolo dalle condizioni degli elementi fisici, secondo i quali era generalmente concepito; inquantochè volle includervi l'elemento spirituale delle coscienza di nazionalità, e proclamò in faccia al mondo civile che, quando un popolo ha la convinzione, la coscienza, il sentimento di costituire la stessa famiglia nazionale, ha il diritto a elevarsi a Stato indipendente da qualunque predominio. [...] In modo che, secondo il Mancini, noi siamo unica nazione, non solo perchè chiusi fra le Alpi ed il Mare, ma perchè abbiamo la coscienza di appartenere allo stesso sodalizio nazionale." In: MANCINI, Pasquale Stanislao. Discorsi Parlamentari. Roma: tipografia della Camera dei deputati, vol. VIII, 1897, p. 653-654. O mesmo Carnazza Amari escreveu um volume sobre Direito Internacional, apontando na sua introdução que o princípio de nacionalidade estava triunfando na Europa da época pós-Congresso de Viena. O princípio de nacionalidade irrompia no panorama e exigia "um novo direito internacional". In: CARNAZZA AMARI, Giuseppe. Elementi di diritto internazionale. Catania: Crispo e Russo editori, 1866, p. 23.

${ }^{17}$ Tradução livre de: "[...] il sentimento che ela acquista di sè medesima e che la rende capace di costituirsi al di dentro e di manifestarsi al di fuori. [....] essa é il Penso, dunque esisto de' filosofi, applicato alle Nazionalità."

${ }^{18}$ Fala-se por causa disso de uma impostaçáo voluntarista de Mancini em oposiçáo àquela alemã que valoriza os elementos materiais que constituem a nação, podendo denominar essa abordagem de naturalista. Para uma leitura que expóe uma visão peculiar quanto à essência da nação descrita por Mancini, ver: CURCIO, Carlo. Nazione e autodecisione dei popoli. Due idee nella storia. Milano: Giuffrè, 1977. O autor, ao analisar os elementos que compóem a nação afirma que, contrariamente a quem define a essência espiritual da nação manciniana, ele vê, além desse elemento espiritual, uma 
A nacionalidade para Mancini não é apenas um sentimento - que origina o patriotismo e que é ligado ao momento instintivo do Risorgimento - sendo também um direito dos que a possuem, daqueles que são unidos em uma mesma nação, e configurando-se, ademais, como um dever, a ser exercido nas hipóteses em que tal direito seja transgredido. A nacionalidade, segundo Mancini, é o exercício coletivo da liberdade que cada homem possui, de fato:

O direito da nacionalidade, portanto, nada mais é do que a própria liberdade do indivíduo estendida ao comum desenvolvimento do agregado orgânico dos indivíduos que formam as naçóes; a nacionalidade nada mais é do que a explicaçáo coletiva da liberdade e, todavia, santa e divina coisa como a própria liberdade. Onde em cada nação, tal liberdade não pode ter outro limite, que onde começa a violação da igual liberdade que é indispensável respeitar em todas as outras. Até não se encontrar aquela lesão da vida livre de outra nação, a conservação e o livre desenvolvimento da primeira nacionalidade é um direito incontrastável. [...] Mas quando o exercício da liberdade segundo determinada direção percebe-se ser necessário para própria vida da humanidade e para seu objetivo, nos caminhos aos quais as leis imutáveis da sua natural constituição a chamam; ela é muito mais do que um direito para os homens, é um dever ${ }^{19}$ (1851, p. 41-42).

Como é possível depreender das palavras do jurista, além de um direito, a nacionalidade era concebida como um dever jurídico que exigia esforços na hipótese em que o exercício daquela liberdade individual e coletiva fosse impedido.

importância maior do elemento natural. O autor Benvenuto Donati aponta na doutrina italiana de Direito Internacional o mérito de ter realçado a unidade espiritual como elemento da nação: "Non sono tanto gli elementi obiettivi, che da soli possan servire a spiegare l'esistenza di un gruppo umano, compatto e differenziato, al quale si conviene il nome di nazione." In: DONATI, Benvenuto. Dal principio di nazionalità al principio corporativo. Roma: Stabilimento Tipografico Centrale, 1950. p. 6.

${ }^{19}$ Tradução livre de: "Il diritto di nazionalità adunque non é che la stessa libertà dell'individuo estesa al comune sviluppamento dell'aggregato organico degl'individui che formano le nazioni; la nazionalità non é che la esplicazione collettiva della libertà. Laonde in ciascuna nazione questa libertà non può avere altro limite, che dove cominci la violazione della eguale libertà che é forza rispettare in tutte le altre. Finché quella lesione della libera vita di un'altra nazione non sincontra, la conservazione ed il libero sviluppamento della prima nazionalità é un diritto incontrastabile. [...] Ma quando l'esercizio della libertà secondo una determinata direzione scorgesi inoltre necessario alla vita stessa dell'umanità ed al suo fine, nelle vie per le quali le leggi immutabili della sua natural costituzione la chiamano; essa é assai più che un diritto, è un devere". 
Após ter elencado as características constitutivas do princípio de nacionalidade ou da nação, Mancini ressalta que ela deve possuir coerência interna, uma boa constituiçáo moral e também, para com o exterior, se manifestar como um corpo independente isente do arbítrio das outras naçôes. Isso se traduz na consequência de que a nação deve ser livre para se organizar como melhor acreditar, portanto teoricamente "a livre constituição interna" pode desembocar em uma democracia ou em uma tirania na hipótese em que essa forma de governo seja desejada pelo próprio povo (PENNISI, 1931, p. 11).

Apontando no Estado a causa das desordens que afligiam a comunidade internacional, o jurista pretende analisar o Direito Internacional a partir daquele aglomerado composto por indivíduos, que é a nação. Ao contrário do que ocorria nas doutrinas de Direito Internacional de matriz iluminista e contratualista, o Estado, portanto, vê salientada sua finitude, perdendo a sua conotação de entidade antropomórfica (DAL RI JÚNIOR, 2011). Com efeito, ele agora passa a ser visto como uma entidade em declínio por não ser mais capaz de se apresentar como o sujeito supremo do ordenamento internacional.

Mancini contesta veementemente a ciência internacionalista e de Direito público que considerava o Estado na pessoa dos governos o verdadeiro sujeito de Direito Internacional: o que importava para os expoentes dessa ciência é o que era estabelecido pelos poderes mais altos do Estado, tratando o povo como mercadoria de troca (BIAZI, 2014). Contrapondo-se a essa concepção estatalista, o jurista italiano concebe a nação como um prius lógico, algo que necessariamente e logicamente precede o Estado. Partindo da nação e não mais do Estado, é possível conceber os homens, os povos, e náo mais o governo, sujeitos capazes de ter direitos e deveres, e aptos a decidirem sobre o próprio futuro (BIAZI, 2014). As individualidades de um povo seriam sufocadas também, se além de serem submetidas ao domínio estrangeiro, não fossem elas mesmas artífices do seu próprio destino como corpo político. Como o próprio Mancini observa: "Procureis somente na idéia de Estado a raiz dos direitos e dos deveres internacionais; e sereis levados a conduzir a admitir que no indivíduo estrangeiro não respeiteis o homem e as faculdades que são produto da sua natureza; mas o Governo do qual ele depende"20 (1851, p. 47).

${ }^{20}$ Tradução livre de: "Cercate nella sola idea dello Stato la radice de' diritti e dei deveri internazionali; $e$ sarete condotti ad ammettere che nell'invididuo straniero non rispettate l'uomo e e facoltà che sono un prodotto della sua natura, ma il Governo dal quale dipende". 
O Estado como entidade criticada por Mancini é aquele que é resultado de conquistas, usurpaçóes e intervençóes em um determinado território que fazem com que se alterem aqueles confins naturais que delimitam uma nação entendida aqui como aglomerado de indivíduos que possuem as mesmas características físicas e a unidade moral que os conduz a serem conscientes de formar uma mesma entidade coletiva. A Nação configura-se como uma obra divina e natural, sujeito natural e necessário em contraposição ao Estado, sujeito artificial e arbitrário, obra da força. A nacionalidade geraria entre os homens algumas relaçóes jurídicas espontâneas e naturais, enquanto o Estado, como fruto de um pacto político, de um contrato, de um ato fictício, geraria relaçôes artificiais ${ }^{21}$ (DROETTO, 1954, p. 205).

As naçóes devem se respeitar reciprocamente: isso prevê que cada uma delas não viole a independência das demais. Conforme Sereni, da teoria de Mancini derivam algumas consequências: a) cada nação deveria constituir um Estado e um apenas; b) cada naçáo deveria ser livre em se organizar como um Estado independente; c) naçóes, e, portanto Estados que consistem nelas, deveriam ser todas iguais; d) naçôes e Estados consistindo dessas deveriam ser independentes, sendo proibido para os Estados intervir nos assuntos internos de outros e) tratados contrários ao princípio de nacionalidade, de igualdade e de independência deveriam ser revisados ${ }^{22}$ (SERENI, 1943).

O território de cada nação é suposto como inviolável, portanto são iguais nesse sentido e isso faz com que não seja violada nenhuma lei suprema. Mancini utiliza-se da fórmula de Kant para asseverar a igualdade e liberdade das naçóes: a coexistência e concordância da liberdade de todos os homens transforma-se - no campo do Direito Internacional - na coexistência e concordância da liberdade de todas as nacionalidades.

${ }^{21} \mathrm{O}$ autor explica que a escola italiana reconhece na Nação e náo no Estado aquela qualidade de Direito público que a primeira possui por si mesma, ou seja, por natureza, aquela capacidade jurídica que o Estado obtém convencionalmente quando é instituído. Ver também a contribuição de Luigi Nuzzo: "Per un giurista non era necessario ricorrere agli artifici di un patto politico o di un contratto sociale il cui inevitabile approdo era solo un soggetto statale con una forte vocazione potestativa e oppressiva." In: NUZZO, Luigi. Origini di una scienza: diritto Internazionale e colonialismo nel XIX secolo. Frankfurt am Main: Vittorio Klostermann, 2012. p. 93. Outro autor, Carlo Curcio, observa que para Mancini o Estado era obra da força e a nação da Providência, aquele instrumento de guerra, a nação arma de paz. In: CURCIO, Carlo. Nazione e autodecisione: due idee nella storia. Milano: Giuffrè, 1977. p. 150.

${ }^{22}$ Outra consequência seria a uniáo das naçóes em uma organizaçáo capaz de resolver os litígios entre elas e de eliminar a injustiça por meio de procedimentos de soluçáo pacífica, como a arbitragem. 


\section{CONSIDERAÇÕES FINAIS}

Colocando-se em uma posição intermediária entre a ideia de nacionalidade "natural" desenvolvida em Alemanha - a qual conferia centralidade a fatores naturalísticos tais como comunhão de língua, raça, religião, geografia - e aquela "voluntarista" - teorizada na França, e que apelava à vontade dos povos de se constituírem em Nação - Mancini colocava a essência da Nação nos elementos materiais como os fatores étnicos e raciais, mas, sobretudo, problematizando a essências desses em um perfil subjetivo espiritual, a "consciência" da nacionalidade, sem a qual até os fatores naturais teriam continuado a ser "matéria inerte". A insistência sobre o elemento psicológico - como anteriormente evidenciado - era funcional a reivindicar para o povo italiano da época a natureza de Naçáo, embora ainda não constituída por causa das contingências políticas, em Estado; justamente com Mancini é que a Nação posta acima do direito do Estado irrompia na ciência do Direito Internacional. Para Mancini, o princípio de nacionalidade era, portanto, funcional à individuação do fundamento do relacionamento entre indivíduo e autoridade: somente como consequência do fato de ser cidadão de uma Nação, o mesmo poderia se submeter à soberania estatal. Na visão de Mancini, acima do Direito do Estado assentava-se o da Nação, que não podia "se extinguir ou suprimir por vontade e poder do Estado." Daí advinha a justificação da distinção entre Estados "obra da força" e como tais fadados a se desfazer, e Estados criação da "natureza imutável e eterna, os Estados nacionais".

Ainda, o jurista apresenta as naçóes não como entidades estáticas, mas na condição de sujeitos dinâmicos que necessitam de leis e instituiçôes para realizar as suas próprias tarefas, tornando-se corpos políticos da vida internacional. Antes disso, porém, elas já existem e são verdadeiramente o fundamento de um Direito Internacional que se propóe como ciência, tendo em vista o objetivo de garantir uma maior estabilidade das Relaçôes Internacionais. Na opinião de Mancini, apenas as Naçôes são susceptíveis de garantirem essa estabilidade, constituindo a fonte dos direitos e dos deveres internacionais por excelência. Os verdadeiros sujeitos do Direito Internacional seriam, portanto, não mais os governos e os Estados, mas os povos, agora regidos pelas leis que descendem do princípio de nacionalidade, verdadeira "constituição orgânica da humanidade". 


\section{REFERÊNCIAS}

BIAZI, Chiara Antonia Sofia Mafrica. Representaçóes do princípio de nacionalidade na doutrina internacionalista do século XIX na construção do princípio de autodeterminação dos povos: continuidades e rupturas em um discurso liberal. 2014. Dissertação (Mestrado em Direito) - Programa de Pós-Graduação em direito, Universidade Federal de Santa Catarina, Florianópolis, 2014.

CARLE, Giuseppe. Pasquale Stanislao Mancini e la teoria psicologica del sentimento nazionale. In: Atti della R. Accademia dei Lincei, classe di scienze fisiche e morali, VI, Roma. p. $548-567,1889$.

CARNAZZA AMARI, Giuseppe. Elementi di diritto internazionale. Catania: Crispo e Russo Editori, 1866.

COLAO, Floriana. L' “idea di Nazione” nei giuristi italiani tra Ottocento e Novecento. Quaderni Fiorentini, XXX, p. 255-360, 2001.

CURCIO, Carlo. Nazione e autodecisione: due idee nella storia. Milano: Giuffrè, 1977.

. Nazione, Europa, Umanità: saggi sulla storia dell'idea di nazione e del principio di nazionalità in Italia. Milano: Giuffré, 1950.

DAL RI JÚNIOR, Arno. A nação contra o Estado. A ciência de direito internacional no "Risorgimento" italiano. Anuário brasileiro de direito internacional, vol. 1, p. 69-97, 2011.

DONATI, Benvenuto. Dal principio di nazionalità al principio corporativo. Roma: Stabilimento Tipografico Centrale, 1950.

DROETTO, Antonio. Pasquale Stanislao Mancini e la scuola italiana di diritto internazionale del XIX secolo. Milano: Giuffré, 1954.

FRANCOVICH, Carlo. Il Risveglio delle nazionalità nel periodo napoleonico. In: Atti del convegno Internazionale di Portoferraio (21-23 febbraio 1981). Pisa: Giardini Editori, 1981.

GIOBERTI, Vincenzo. Il gesuita moderno. Losanna: S. Bonamici e compagni, 1846. Vol. 5. HOBSBAWM, Eric J. Nazioni e nazionalismo dal 1780. Torino: Giulio Einaudi Editore, 1991.

LIOY, Diodato. Del principio di nazionalità guardato dal lato della storia e del diritto pubblico. Napoli: Presso Giuseppe Marghieri, 1863.

LOPEZ DE ONATE, Flavio. Introduzione. In: MANCINI, Pasquale Stanislao. Saggi sulla nazionalità. Bergamo: Sestante, 1944.

MANCINI, Pasquale Stanislao. Della nazionalità come fondamento del diritto delle genti. Torino: Tipografia Eredi Botta, 1851. 
MANCINI, Pasquale Stanislao. Discorsi Parlamentari. Roma: Tipografia della Camera dei Deputati, 1897. Vol. VIII. . Direito Internacional (Diritto Internazionale. Prelezioni), Ijuí: Ed. Unijuí, 2003.

MAZZINI, Giuseppe. Istruzione generale per gli affratellati nella "Giovane Italia”. In Scritti editi ed inediti. Edizione nazionale. Imola: Galeati, 1935. Vol. II.

NUZZO, Luigi. Origini di una scienza: diritto Internazionale e colonialismo nel XIX secolo. Frankfurt am Main: Vittorio Klostermann, 2012.

PENNISI, Pasquale. Della applicazione del principio di nazionalità ai popoli di civiltà non europea. Padova: Cedam, 1931.

ROMAGNOSI, Gian Domenico. Prodromo della vita degli Stati. In Opere. Milano: Ed. De Giorgi, 1842. Vol. III.

SERENI, Angelo Piero. The italian conception of international law. Nova York: Columbia University Press, 1943.

TAPARELLI D’AZEGLIO, Luigi. Della nazionalità. Genova: Ponthenier, 1849.

VON BOGDANDY, Armin; HAUBLER, Stefan. Nations. In: The Max Planck Encyclopedia of Public International Law. Oxford: Oxford University Press, 2012.

WEILL, Georges. L'Europe du XIX siècle et l'idée de nationalité. Paris: Éditions Albin Michel, 1938. 